\title{
LA PROTECCIÓN DE DATOS PERSONALES DE LAS PERSONAS FÍSICAS EN EL ÁMBITO DE LA UNIÓN EUROPEA. ESPECIAL REFERENCIA AL TRATAMIENTO BASADO EN EL CONSENTIMIENTO DEL AFECTADO
}

\author{
THE PROTECTION OF PERSONAL DATA OF PHYSICAL PERSONS IN THE FIELD OF THE \\ EUROPEAN UNION. SPECIAL REFERENCE TO THE TREATMENT BASED ON THE \\ CONSENT OF THE CONCERNED
}

\author{
David Vallespín Pérez \\ Catedrático de Derecho Procesal \\ Universitat de Barcelona \\ E-mail: dvallespin@ub.edu
}

Convidado

RESUMEN: El presente artículo se centra en el análisis de la protección de datos en el ámbito de la Unión Europea, con especial referencia al tratamiento basado en el consentimiento del afectado tras la aprobación del Reglamento (UE) 2016/679 del Parlamento y del Consejo, de 27 de abril de 2016 y la reciente entrada en vigor, en el caso español, de la Ley Orgánica 3/2018, de 5 de diciembre, de Protección de Datos Personales y Garantía de los Derechos Digitales.

Palabras Clave: Protección de Datos Personales; Consentimiento; Derechos de los Afectados.

ABSTRACT: This article focuses on the analysis of data protection in the European Union, with special attention to the treatment based on the consent of the affected party after the approval of Regulation (EU) 2016/679 of the Parliament and the Council of April 27, 2016; and the recent entry into force, in the Spanish case, of the Law No. 3/2018, of December 5, about the Personal Data Protection and the Digital Rights Guarantee.

Keywords: Personal Data Protection; Consent; Rights of the Interested Parties.

SUMARIO: 1 La protección de datos personales de las personas físicas en el ámbito de la Unión Europea. Especial referencia a los principios clave del tratamiento y a los derechos de las personas; 2 Legitimación del tratamiento (planteamiento general); 3 Tratamiento basado en el consentimiento; Índice bibliográfico. 


\section{LA PROTECCIÓN DE DATOS PERSONALES DE LAS PERSONAS FÍSICAS EN EL ÁMBITO DE LA UNIÓN EUROPEA. ESPECIAL REFERENCIA A LOS PRINCIPIOS CLAVE DEL TRATAMIENTO Y LOS DERECHOS DE LAS PERSONAS}

La protección de las personas físicas en relación al tratamiento de los datos personales ${ }^{1}$ es, en el ámbito de la Unión Europea, un derecho fundamental (art. 8.1 de la Carta de los Derechos Fundamentales de la Unión Europea y art. 16.1 del Tratado de Funcionamiento de la Unión Europea $)^{2}$. Ahora bien, este derecho fundamental autónomo en que consiste la protección de datos personales de las personas físicas no es un derecho absoluto, pues debe analizarse en orden a su función en la sociedad y en equilibro con otros derechos fundamentales, con arreglo al principio de proporcionalidad ${ }^{3}$.

En esta línea interpretativa, también apreciable en numerosos textos constitucionales de los Estados miembros de la Unión Europea como es el caso, por ejemplo, de la Constitución Española de 1978 (art. $18.4 \mathrm{CE})^{4}$, no resulta nada extraño que la propia Unión Europea, ya mediante la Directiva 95/46/CE del Parlamento Europeo y del Consejo ${ }^{5}$, enfrentase la necesidad de armonizar la protección de los derechos y libertades fundamentales de las personas físicas en relación con las

\footnotetext{
${ }^{1}$ De conformidad con el art. 4 RGPD, dato personal es toda información sobre una persona física identificada o identificable (el interesado). Un dato de carácter personal es cualquier información numérica, alfabética, gráfica, fotográfica, acústica o de cualquier otro tipo concerniente a personas identificadas o identificables. Son considerados como tales los datos identificativos de las personas (nombre, apellidos, dirección, teléfono, correo electrónico, firma, etc), los relativos a sus características personales o sociales (edad, estado civil, etc); relacionados con el empleo (cargo, profesión, historial, etc); la información comercial, económica y financiera y de seguros (vgr. un número de cuenta o tarjeta de crédito); fotografías o videos, la matrícula de un vehículo, o la dirección IP. Y el tratamiento de estos datos personales supone, como también contempla el art. 4 RGPD, cualquier operación o conjunto de operaciones realizadas sobre dichos datos o conjuntos de datos, ya sea por procedimientos automatizados o no, como la recogida, registro, organización, estructuración, conservación, adaptación o modificación, extracción, consulta, utilización, comunicación para transmisión, difusión o cualquier otra forma de habilitación de acceso, cotejo o interconexión, limitación, supresión o destrucción. El tratamiento de los datos personales no viene limitado al automatizado, sino que también puede incluir el manual.

${ }^{2}$ Art. 8 Carta de los Derechos Fundamentales de la Unión Europea: “1. Toda persona tiene derecho a la protección de los datos de carácter personal que la conciernen. 2. Estos datos se tratarán de modo leal, para fines concretos y sobre la base del consentimiento de la persona afectada o en virtud de otro fundamento legítimo previsto por la ley. Toda persona tiene derecho a acceder a los datos recogidos que le conciernan y a obtener su rectificación. 3. El respeto de estas normas estará sujeto al control de una autoridad independiente”. Art. 16 del Tratado de Funcionamiento de la Unión Europea: "1. Toda persona tiene derecho a la protección de los datos de carácter personal que le conciernan. 2. El Parlamento Europeo y el Consejo establecerán, con arreglo al procedimiento legislativo ordinario, las normas sobre protección de las personas físicas respecto del tratamiento de datos de carácter personal por las instituciones, órganos y organismos de la Unión, así como por los Estados miembros en el ejercicio de las actividades comprendidas en el ámbito de aplicación del Derecho de la Unión, y sobre la libre circulación de estos datos. El respeto de dichas normas estará sometido al control de autoridades independientes. Las normas que se adopten en virtud del presente artículo se entenderán sin perjuicio de las normas específicas previstas en el art. 39 del Tratado de la Unión Europea".

${ }^{3}$ Acerca de la configuración de este derecho a la protección de datos de las personas físicas como derecho fundamental, por todas, véanse: STC 94/1998, de 4 de mayo (BOE núm. 137, de 9 de junio de 1998). Sala Segunda. Recurso de amparo 840/1995; y STC 292/2000, de 30 de noviembre (BOE núm. 4, de 4 de enero de 2001). Pleno. Recurso de inconstitucionalidad 1463/2000: "derecho autónomo e independiente que consiste en un poder de disposición y control sobre los datos personales que faculta a la persona para decidir cuáles de esos datos proporciona a un tercero, sea el Estado o un particular, o cuáles puede éste recabar de un tercero, y que también permite al individuo saber quién posee esos datos personales y para qué, pudiendo oponerse a esa posesión o uso”. Sobre su consideración como derecho no absoluto (Considerando 4 que lleva a la aprobación del RGPD).

${ }^{4}$ Art. 18.4 de la Constitución Española de 1978: "La ley limitará el uso de la informática para garantizar el honor y la intimidad personal y familiar de los ciudadanos y el pleno ejercicio de sus derechos".

${ }^{5}$ Directiva 95/46/CE del Parlamento y del Consejo, de 24 de octubre de 1995, relativa a la protección de las personas físicas en lo que respecta al tratamiento de datos personales y a la libre circulación de estos datos (DO L 281 de 23.11.1995).
}

Revista de Direito Brasileira | Florianópolis, SC | v. 22 | n. 9 | p.90-100 |Jan./Abr. 2019 
actividades del tratamiento de datos de carácter personal y garantizar la libre circulación de dichos datos entre sus Estados miembros.

La integración económica y social resultante del funcionamiento de mercado interior, unida a la rápida evolución tecnológica y la globalización, han facilitado aún más la libre circulación de datos personales dentro de la Unión, así como su transferencia a terceros países y organizaciones internacionales; pero también han puesto sobre la mesa la necesidad de garantizar, cada vez más, un alto nivel de protección y seguridad de unos datos personales que circulan a gran escala y que se ven sometidos a riesgos de confidencialidad (la información no debe ser revelada, accidental o voluntariamente, a personas no autorizadas), integridad (la información no puede sufrir modificaciones no consentidas), o disponiblidad (la información debe ser accesible para las personas autorizadas); que hacen necesario ponderar el nivel de resilencia de cada organización, esto es, su capacidad para dar respuesta ante las brechas expuestas mediante la adopción de aquellas medidas de seguridad que se consideren apropiadas y proporcionadas en cada caso concreto.

De este modo, se ha planteado una aproximación a la gestión del riesgo en la que cabe identificar las amenazas, evaluar los riesgos, esto es, la probabilidad de que la amenaza se materialice y cuál sea su impacto, y proceder a tratarlos, es decir, a tomar en consideración las medidas a aplicar en aras a reducir la probabilidad de que la amenaza se materialice sobre los datos personales, así como el impacto que ésta pueda llegar a tener.

Situación ésta, por otra parte, que ha conducido al legislador europeo, así como al español, en su reciente LOPD de 2018, a concretar aquellas obligaciones que corresponden en esta materia al responsable del tratamiento ${ }^{6}$, aquellas otras que son propias del encargado del tratamiento ${ }^{7}$; y las funciones que corresponden al Delegado de Protección de Datos ${ }^{8}$; así como a fijar un régimen sancionador en el que se han elevado sustancialmente los tipos sancionadores; se han delimitado los sujetos responsables (están sometidos a él los responsables del tratamiento, los encargados de éste, los representantes de los responsables o encargados no establecidos en el ámbito de la UE, las entidades de certificación y las entidades acreditadas de supervisión de los códigos de conducta); las infracciones se han clasificado en muy graves, graves y leves; y se han previsto multas administrativas de cuantía económica sustancial (según el tipo de infracción se sancionarán con la cantidad máxima de 10 millones de euros o, tratándose de una empresa, con una cuantía equivalente al $2 \%$ como máximo de su volumen de negocio total anual del ejercicio financiero anterior, optándose por la de mayor cuantía; o bien con una cantidad máxima de 20 millones de euros o, tratándose de una empresa, de una cuantía equivalente al $4 \%$ como máximo del volumen de negocio anual, optándose por la de mayor cuantía $)^{9}$.

Todo ello ha hecho necesario que la propia Unión Europea, yendo más allá de lo ya apuntado en la Directiva 95/46/CE, haya tomado conciencia de la necesidad de dotarse de un marco más sólido en orden a la protección de los datos personales de las personas físicas en el que sea posible compatibilizar, de una parte, la necesidad de generar aquella confianza que permita a la economía digital desarrollarse en el mercado; y, de otra, la obligación de que las personas físicas, en paralelo, sigan siendo dueñas del control de sus propios datos personales.

Constatada, fruto de la implementación de la Directiva 95/46/CE, una fragmentada aplicación de la protección de datos personales en la Unión Europea que bien pudo contribuir a obstaculizar el ejercicio de actividades económicas a nivel de la Unión, falsear la competencia e impedir que las autoridades cumplan con las funciones que les incumben en virtud del Derecho de

\footnotetext{
${ }^{6}$ El responsable del tratamiento es aquella persona física o jurídica, autoridad pública, servicio u organismo que, solo o junto con otros, determina los fines y medios del tratamiento (art. 4 RGPD).

${ }^{7}$ El encargado del tratamiento es aquella persona física o jurídica, autoridad pública, servicio u otro organismo que trata los datos personales por cuenta del responsable del tratamiento (at. 4 RGPD).

${ }^{8}$ El delegado de protección de datos actúa como catalizador del conjunto de procesos indispensables para asegurar el cumplimiento de las exigencias en materia de protección de datos, cumpliendo con una función de soporte en atención a sus conocimientos especializados (sobre sus funciones, véase, el art. 39 RGPD).

${ }^{9}$ Arts. 70 y siguientes de la LOPD, así como arts. 83 y 84 RGPD.
}

Revista de Direito Brasileira | Florianópolis, SC | v. 22 | n. 9 | p. 90-100 |Jan./Abr. 2019 
la Unión; se hizo patente, en el Espacio Económico Europeo, que en orden a garantizar un nivel uniforme y elevado de protección de las personas físicas y eliminar los obstáculos a la libre circulación de datos personales dentro de la Unión, el nivel de protección de los derechos y libertades de las personas físicas en orden al tratamiento de dichos datos debe ser equivalente, coherente y homogéneo en los diferentes Estados miembros ${ }^{10}$.

La protección efectiva de los datos personales en la UE exige, en consecuencia, que se refuercen y especifiquen los derechos de los interesados y las obligaciones de quienes tratan y determinan el tratamiento de los datos de carácter personal, y que en los Estados miembros se reconozcan poderes equivalentes para supervisar y garantizar el cumplimiento de las normas relativas a la protección de los datos de carácter personal y las infracciones se castiguen con sanciones equivalentes. Estos objetivos irrenunciables constituyen la razón de ser de la elaboración del Reglamento (UE) 2016/679 del Parlamento Europeo y del Consejo, de 27 de abril de 2016, relativo a la protección de las personas físicas en lo que respecta al tratamiento de los datos personales y a la libre circulación de estos datos CE (Reglamento General de Protección de Datos) ${ }^{11}$ y por el que se deroga la Directiva 95/46/CE.

Con este RGPD cambia radicalmente la forma de regular la protección de datos personales de las personas físicas, pues se opta no solo por otorgar el máximo poder de gestión al titular del dato; sino también por obligar a las empresas, organismos y administraciones, en ejecución de un sistema proactivo y profesionalizado, a hacer cambios estructurales y organizativos de gran calado en orden a garantizar, en cuanto derecho fundamental, la protección de datos ${ }^{12}$.

Con todo, no son pocas las dudas, incertidumbres y miedos que sobrevuelan sobre su implementación práctica efectiva, pues su notable rigidez, sin que ello suponga obviar sus aspectos positivos, bien puede terminar por poner en riesgo la competitividad económica de las empresas de la Unión Europea en relación a las americanas y asiáticas; suponer un cierto límite en cuanto a las expectativas de progreso y avance en el ámbito de la investigación biomédica y genética; o provocar un relativo freno en orden a la aplicación, que parece imparable, de la inteligencia artificial en aras a diseñar y comercializar diferentes servicios, máxime en un mercado dominado, cada día más, por la economía colaborativa o por plataformas ${ }^{13}$, así como por el tratamiento de datos personales en el ciberespacio ${ }^{14}$.

Este Reglamento ya aplicable en España desde el 25 de mayo de 2018, se ha acompañado, muy recientemente, de la aprobación de la Ley Orgánica 3/2018, de Protección de Datos, de 5 de diciembre de $2018^{15}$, cuyo objeto, como así dispone su art. 1 es doble ${ }^{16}$ : adaptar el ordenamiento jurídico español al RGPD, así como completar sus disposiciones; y garantizar los derechos digitales de la ciudadanía conforme al mandato derivado del art. 18.4 de la Constitución Española de 1978.

\footnotetext{
${ }^{10}$ Considerandos 9 y 10 que han conducido a la aprobación del RGPD.

${ }^{11}$ Considerando 13 que lleva a la aprobación del RGPD.

${ }^{12}$ Considerando 78 que conduce al RGPD.

${ }^{13}$ VALLESPÍN PÉREZ, D. El régimen profesional de los trabajadores autónomos y sus especialidades, Bosch, Barcelona, 2018, págs. 41 y ss.

${ }^{14}$ Sobre la protección de consumidores y usuarios en el sector de las telecomunicaciones véase, por ejemplo: VALLESPÍN PÉREZ, D. Litigios sobre consumo: acciones colectivas y especialidades procesales, Bosch, Barcelona, 2018, págs. 255 y ss.

${ }^{15}$ Ley Orgánica 3/2018, de 5 de diciembre, de Protección de Datos Personales y garantía de los derechos digitales (BOE, de 6 de diciembre de 2018), núm. 294, Sección 1, págs. 119788 y ss. Sobre el desarrollo parlamentario de la LOPD véase, por todos: MARTÍNEZ VÁZQUEZ, F. “La tramitación parlamentaria de la Ley Orgánica de Protección de Datos Personales y Garantía de los Derechos Digitales”, en Tratado de Protección de Datos, dirigida por Rallo Lombarte, Tirant lo blanch, Valencia, 2019, págs. 53 y ss.

16 Por lo que hace referencia a los objetivos de la normativa europea y nacional sobre protección de datos de las personas físicas, véase el análisis realizado por: AMÉRICO ALONSO, J. “Objeto y ámbito de aplicación”, en Tratado de Protección de Datos, dirigida por Rallo Lombarte, Tirant lo blanch, Valencia, 2019, págs. 79 y ss.
}

Revista de Direito Brasileira | Florianópolis, SC | v. 22 | n. 9 | p.90-100 |Jan./Abr. 2019 
De conformidad con esta nueva normativa, la protección de datos personales de las personas físicas, bajo el obligado respeto de un amplio elenco de principios ${ }^{17}$, debe comportar que éstos sean: a) tratados de manera lícita (principio de licitud) leal y transparente (principio de transparencia) ${ }^{18}$; b) recogidos con fines determinados, explícitos y legítimos, no siendo tratados ulteriormente de manera incompatible con dichos fines (principio de limitación de la finalidad) ${ }^{19}$; c) adecuados, pertinentes y limitados a lo necesario en relación con los fines para los que son tratados (principio de minimización de datos) ${ }^{20} ; \mathrm{d}$ ) exactos y, si fuera necesario, actualizados, para lo que se adoptarán todas las medidas razonables para que se supriman o rectifiquen sin dilación los datos personales que sean inexactos con respecto a los fines para los que se tratan (principio de exactitud $)^{21}$; e) contenidos de forma que se permita la identificación de los interesados durante no más tiempo del necesario para los fines del tratamiento de los datos personales (principio de limitación del plazo de conservación) ${ }^{22}$; f) tratados de tal manera que se garantice una seguridad adecuada de los datos personales, incluida la protección contra el tratamiento no autorizado o ilícito y contra su pérdida, destrucción o daño accidental, mediante la aplicación de medidas técnicas y organizativas apropiadas (principio de integridad y confidencialidad) ${ }^{23}$; g) ajustados a un principio de responsabilidad proactiva ${ }^{24}$, en tanto que el responsable del tratamiento es el responsable del cumplimiento de los principios aplicables al tratamiento de datos personales, pero también debe ser capaz de demostrar su cumplimiento, de tal forma que no basta con cumplir la normativa de protección, sino que, además, también hay que demostrar dicho cumplimiento con evidencias tales como, por ejemplo, la muestra de consentimientos, o la demostración de la calidad y seguridad del servicio; h) regidos por un principio de protección de datos por defecto y desde el inicio ${ }^{25}$, pues se deberán adoptar aquellas medidas que garanticen el cumplimiento de la norma desde el mismo momento en que se diseñe una empresa, producto, servicio o actividad que implique el tratamiento

17 Art. 5 RGPD y arts. 4 y siguientes de la LOPD. Sobre dichos principios, véanse: PUENTE ESCOBAR, A. "Principios y licitud del tratamiento", en Tratado de Protección de Datos, dirigida por Rallo Lombarte, Tirant lo blanch, Valencia, 2019, págs. 115 y ss; así como MARTOS, N. “Principios (arts. 6 a 11)”, en El nuevo marco regulatorio derivado del Reglamento Europeo de Protección de Datos, coordinada por López Calvo, Bosch, Barcelona, 2018, Capítulo XV.

${ }^{18}$ Este principio de transparencia debe analizarse en relación con el llamado "derecho de información”. En esta línea, el art. 11 LOPD dispone, muy gráficamente, que cuando los datos personales sean obtenidos del afectado el responsable del tratamiento podrá dar cumplimiento al deber de información establecido en el art. 13 RGPD, facilitando al afectado información básica (identidad del responsable del tratamiento y de su representante, en su caso; la finalidad del tratamiento; y la posibilidad de ejercer los derechos establecidos en los arts. 15 a 22 del RGPD) e indicándole una dirección electrónica u otro medio que permita acceder de forma sencilla e inmediata al resto de la información; que si los datos obtenidos del afectado van a ser tratados para elaborar perfiles, la información básica referida deberá completarse con la mención a esta circunstancia; y que cuando los datos personales no se hayan obtenido del afectado, el responsable podrá dar cumplimiento a este deber de información facilitándole la información básica antes referida (la prevista para los casos en que los datos son obtenidos del afectado, indicándole una dirección de correo electrónico u otro medio que permita acceder de forma sencilla e inmediata a la restante información, y añadiéndose también la referencia a las categorías de los datos objeto de tratamiento y las fuentes de su procedencia).

${ }^{19}$ Art. 5.1.b RGPD y art. 4 LOPD.

${ }^{20}$ Art. 5.1.c RGPD.

${ }^{21}$ Art. 5.1.d RGPD y art. 4 LOPD.

${ }^{22}$ Art. 5.1.e) RGPD,

${ }^{23}$ Art. 5.1.f) RGPD y art. 5 LOPD.

${ }^{24}$ Arts. 24, 25, 26, 27 y 28 RGPD y arts. 28, 29, 30, 31, 32 y 33 LOPD. Sobre este particular, véanse: ÁLVAREZ HERNANDO, J. Practicum. Protección de Datos 2018, Thomson Reuters, Madrid, 2017, págs. 245 y ss; BAJO, J.C. “Consideraciones sobre el principio de responsabilidad proactiva y diligencias (accountability)”, en El nuevo marco regulatorio derivado del Reglamento de Protección de Datos, coordinada por López Calvo, Bosch, Barcelona, 2018, Cap. X; NÚÑEZ GARCÍA, L. “Responsabilidad y obligaciones del responsable y del encargado del tratamiento”, en Tratado de Protección de Datos, dirigida por Rallo Lombarte, Tirant lo blanch, Valencia, 2019, págs. 353 y ss.

${ }^{25}$ Art. 25 RGPD. Sobre su significado e implicaciones, véase: DUASO CALÉS, R. "Los principios de protección de datos desde el diseño y la protección de datos por defecto”, en Reglamento General de Protección de Datos: hacia un nuevo modelo europeo de privacidad, coordinada por María Álvarez Caro - Recio Gayo, y dirigida por José Luis Pilar Mañas, Ed. Reus, Madrid, 2017, págs. 295 y ss.

Revista de Direito Brasileira | Florianópolis, SC | v. 22 | n. 9 | p. 90-100 |Jan./Abr. 2019 
de datos, todo lo cual puede llegar a incluir, en determinadas circunstancias, evaluaciones de impacto; y dichas medidas deberán ser aplicadas por el responsable con anterioridad al inicio del tratamiento y también cuando éste ya se encuentre en pleno desarrollo; e i) sometidos al principio de enfoque del riesgo ${ }^{26}$, en virtud del cual debe realizarse una valoración objetiva de los riesgos derivados del tratamiento de datos y, en consecuencia, decidir aquellas medidas avanzadas (no obsoletas) que vengan orientadas a mitigar los potenciales riesgos parra con los derechos y libertades de las personas físicas.

Entre los derechos personales de los afectados ${ }^{27}$, guiados por la necesidad de garantizarles el poder de control sobre sus propios datos personales, junto a la transparencia e información al afectado $^{28}$ y a los denominados derechos ARCO (acceso, rectificación, cancelación y oposición) ${ }^{29}$, se han añadido otros nuevos como el derecho a la portabilidad de los datos ${ }^{30}$, el derecho a la limitación en su tratamiento ${ }^{31}$, y el derecho al olvido ${ }^{32}$. Y todo ello, además, con inclusión en la LOPD española de 2018 de los llamados "derechos digitales" de los ciudadanos (arts. 79 a 96) ${ }^{33}$, a no confundir con los derechos de las personas en orden al tratamiento de datos personales de las personas físicas antes referidos, que son predicables en el entorno de internet: la neutralidad en la red, el acceso universal a los derechos a la seguridad y educación digital, el derecho al olvido, a la portabilidad, al testamento digital, a la garantía de la libertad de expresión, el derecho a la aclaración de informaciones en medios digitales, y el llamado derecho a la desconexión digital en el marco del derecho a la intimidad en el uso de dispositivos digitales en el ámbito laboral y la protección de menores en internet.

\section{LA LEGITIMACIÓN DEL TRATAMIENTO (PLANTEAMIENTO GENERAL)}

Para que el tratamiento de los datos personales de las personas físicas sea lícito, éstos deben ser tratados con el consentimiento del interesado o sobre alguna otra base legítima establecida conforme a Derecho, incluida la necesidad de cumplir la obligación legal aplicable al responsable del tratamiento o la necesidad de ejecutar un contrato en el que sea parte el interesado o con objeto de tomar medidas a instancia del interesado con anterioridad a la conclusión del contrato ${ }^{34}$.

\footnotetext{
${ }^{26}$ Art. 32 RGPD.

${ }^{27}$ Para un amplio análisis de estos derechos, véanse, entre otros: ADSUARA, B. "Derechos de rectificación, supresión (olvido) y portabilidad (de los datos) y de limitación y oposición (al tratamiento)", en Tratado de Protección de Datos, dirigida por Rallo Lombarte, Tirant lo blanch, Valencia, 2019, págs. 313 y ss; PUYOL MONTERO, J. "Transparencia de la información y derecho de acceso de los interesados en la nueva normativa de protección de datos”, en Tratado de Protección de Datos, dirigida por Rallo Lombarte, Tirant lo blanch, Valencia, 2019, págs. 275 y ss.

${ }^{28}$ Arts. 13 y 14 RGPD y art. 11 LOPD.

${ }^{29}$ Derecho de acceso (art. 15 RGPD y art. 13 LOPD) - Derecho de Rectificación (art. 16 RGPD y art. 14 LOPD) Derecho de Oposición (arts. 21 y 22 RGPD y art. 18 LOPD).

${ }^{30}$ Art. 20 RGPD y art. 17 LOPD.

${ }^{31}$ Art. 18 RGPD y art. 16 LOPD.

${ }^{32}$ Art. 17 RGPD y art. 15 LOPD.

${ }^{33}$ Sobre la configuración del derecho a la protección de datos personales como precursor de la defensa del individuo ante la sociedad digital, véase, por todos: RALLO LOMBARTE, A. "Del derecho a la protección de datos a la garantía de nuevos derechos”, en Tratado de Protección de Datos, dirigido por el propio autor, Tirant lo blanch, Valencia, 2019, págs. 23 y ss.

34 Considerando núm. 40 que conduce al RGPD. Sobre esta plural legitimación, por todos: FERNÁNDEZSAMANIEGO, J - FERNÁNDEZ-LONGORIA P. "El interés legítimo como principio para legitimar el tratamiento de datos", en Tratado de Protección de Datos, dirigida por Rallo Lombarte, Tirant lo blanch, Valencia, 2019, págs. 169 y ss; PUENTE ESCOBAR, A. “Principios y licitud del tratamiento”, en Tratado de Protección de Datos, ob, cit, págs. 132 y ss; y VILASAU SOLANA, M. "El consentimiento general y de menores”, en Tratado de Protección de Datos, dirigida por Rallo Lombarte, Tirant lo blanch, Valencia, 2019, págs. 197 y ss.
} 
Concretamente, el art. 6 del RGPD, relativo a la licitud del tratamiento dispone que éste será lícito cuando se cumpla alguna de las siguientes condiciones: a) el interesado dio su consentimiento para el tratamiento de sus datos personales para uno o varios fines específicos ${ }^{35}$; $b$ ) el tratamiento es necesario para la ejecución de un contrato en el que el interesado es parte o para la aplicación a petición de éste de medidas precontractuales ${ }^{36}$; c) el tratamiento es necesario para el cumplimiento de una obligación legal aplicable al responsable del tratamiento ${ }^{37}$; d) el tratamiento es necesario para proteger intereses vitales del interesado o de otra persona física; e) el tratamiento es necesario para el cumplimiento de una misión realizada en interés público o en el ejercicio de poderes públicos conferidos al responsable del tratamiento ${ }^{38}$; y el tratamiento es necesario para la satisfacción de intereses legítimos perseguidos por el responsable del tratamiento o por un tercero ${ }^{39}$, siempre que sobre dichos intereses no prevalezcan los intereses o los derechos y libertades fundamentales del interesado que requieran la protección de datos personales, en particular cuando el interesado sea un niño. Sobre este particular, la LOPD ha incorporado ciertos preceptos dirigidos a regular, específicamente, el consentimiento, el tratamiento de datos por obligación legal, y el interés público o ejercicio de poderes públicos (arts. 6 a 10).

\section{TRATAMIENTO BASADO EN EL CONSENTIMIENTO}

Como ya se ha anticipado, una de las bases que legitima un tratamiento de datos personales lícito tiene que ver con la prestación del consentimiento a dicho tratamiento por parte del interesado.

Entendido el consentimiento del interesado como toda manifestación de voluntad libre, específica, informada e inequívoca por la que el interesado acepta, ya sea mediante una declaración o una clara acción afirmativa, el tratamiento de datos personales que le conciernen (art. 4 RGPD); el Reglamento (UE) 2016/679 ha fijado ciertas condiciones para que el tratamiento de datos personales de las personas físicas pueda basarse en dicho consentimiento: el responsable deberá ser capaz de demostrar que aquél consintió el tratamiento de sus datos personales; si el consentimiento del interesado se da en el contexto de una declaración escrita que también se refiera a otros asuntos, la solicitud del consentimiento se presentará de tal forma que se distinga claramente de los demás asuntos, de forma inteligible y de fácil acceso y utilizando un lenguaje claro y sencillo, no siendo vinculante ninguna parte de la declaración que constituya infracción del propio Reglamento; el interesado también tendrá derecho a retirar su consentimiento en cualquier momento y dicha retirada no afectará a la licitud del tratamiento basado en el consentimiento previo a su retirada (antes de dar tal consentimiento el interesado será informado de ello; y deberá ser tan sencillo darlo como retirarlo); y al evaluar si el consentimiento se ha dado libremente, se tendrá en cuenta en la mayor medida posible el hecho de si, entre otras cosas, la ejecución de un contrato, incluida la prestación de un servicio, se supedita al consentimiento del tratamiento de datos personales que no son necesarios para la ejecución de dicho contrato ${ }^{40}$.

\footnotetext{
${ }^{35}$ Por ejemplo, cuando te suscribes a un determinado servicio para recibir una newsletter.

36 Así, por ejemplo, el tratamiento de datos de nombre, apellidos y foto de un trabajador en orden a su tarjeta identificativa de la empresa.

${ }^{37}$ En esta línea cuando, por ejemplo, se facilitan datos tributarios a la AEAT.

${ }^{38}$ Es el caso, por excelencia, mediante el cual se ampara el tratamiento de datos por parte de las Administraciones Públicas.

${ }^{39}$ Piénsese, por ejemplo, en aquellos supuestos en los que se accede a imágenes de video-vigilancia de un parking dirigidas a identificar los daños ocasionados sobre determinado vehículo.

${ }^{40}$ Para un análisis completo acerca del consentimiento del afectado en el RGPD, véase, por todos: ÁLVAREZ HERNANDO, J. Practicum Protección de Datos 2018, ob, cit, págs. 165 y ss.
}

Revista de Direito Brasileira | Florianópolis, SC | v. 22 | n. 9 | p. 90-100 |Jan./Abr. 2019 
De igual forma, dicho Reglamento de la UE también contempla ciertas condiciones aplicables al consentimiento del niño en relación con los servicios de la sociedad de la información (art. 8); un tratamiento particular en su art. 9 para categorías especiales de datos personales (los que revelen el origen étnico o racial, las opiniones políticas, las convicciones religiosas o filosóficas, o la afiliación sindical, y el tratamiento de datos genéticos, datos biométricos dirigidos a identificar de forma unívoca a una persona física, datos relativos a la salud o a la vida sexual $\mathrm{u}$ orientaciones sexuales de una persona física; y una referencia individualizada en orden a los datos personales relativos a condenas o infracciones penales (art. 10).

En orden a estas previsiones incorporadas sobre el consentimiento en el Reglamento (UE) 679/2016, el legislador español, en la Ley Orgánica 3/2018, reiterando, en buena medida, lo contemplado en el Reglamento, ha dedicado su art. 6 al tratamiento basado en el consentimiento, señalando, de una parte, que cuando se pretenda fundar el tratamiento de los datos en el consentimiento del afectado para una pluralidad de finalidades será necesario que conste de manera específica e inequívoca que éste se ha otorgado para todas ellas; $y$, de otra, que no podrá supeditarse la ejecución del contrato a que el afectado consienta el tratamiento de los datos personales para finalidades que no guarden relación con el mantenimiento, desarrollo o control de la relación contractual; su art. 7, al consentimiento de los menores de edad (el tratamiento de los datos personales de un menor de edad únicamente podrá fundarse en el consentimiento cuando sea mayor de catorce años, con la excepción de aquellos supuestos en que la ley exija la asistencia de los titulares de la patria potestad o tutela para la celebración del acto o negocio jurídico en cuyo contexto se recaba el consentimiento para el tratamiento en cuestión; y el tratamiento de datos de menores de catorce años, fundado en el consentimiento, solo será válido si consta el del titular de la patria potestad o tutela, con el alcance que determinen los titulares de la patria potestad o tutela); su art. 9 a las categorías especiales de datos (el solo consentimiento del afectado no bastará para levantar la prohibición del tratamiento de datos cuya finalidad principal sea identificar su ideología, afiliación sindical, religión, orientación sexual, creencias u origen racial o étnico); y su art. 10 al tratamiento de datos de naturaleza penal ${ }^{41}$.

El consentimiento debe darse, como se ha avanzado, en un acto afirmativo que refleje una manifestación de voluntad libre ${ }^{42}$, específica ${ }^{43}$, informada $^{44}$, e inequívoca ${ }^{45}$ del interesado de

\footnotetext{
${ }^{41}$ Para un examen pormenorizado acerca de la formación, prestación y alcance del consentimiento, con especial referencia a la interpretación derivada del Grupo de Trabajo núm. 29, véase, por todos: VILASAU SOLANA, M. "El consentimiento general y de los menores", en Tratado de Protección de Datos, ob, cit, págs. 197 y ss.

${ }^{42}$ El término libre implica elección y control por parte de los interesados. De ahí, por ejemplo, que si dicho consentimiento está incluido como parte no negociable de las condiciones generales, deba concluirse que no ha sido dado libremente. Y lo mismo puede decirse cuando venga amparado en el ejercicio práctico de un desequilibrio de poder entre el interesado y el responsable del tratamiento. El consentimiento solo será válido si el interesado puede realmente elegir y no existe riesgo de engaño, intimidación, coerción o consecuencias negativas importantes como, por ejemplo, sustanciales gastos adicionales.

${ }^{43}$ Un consentimiento para una finalidad muy genérica no es válido. En el caso de prestarse para diferentes fines es obligado ponderar su granulidad o disociación y la obtención de un consentimiento para cada uno de ellos.

${ }^{44}$ El consentimiento debe derivar de una voluntad informada, lo cual es garantía de su correcta formación y prestación. Desde la perspectiva de la configuración de una información por "capas o niveles", en cuanto a la finalidad del tratamiento, en la capa de información básica, resumida, debe incorporarse una descripción sencilla de los fines del tratamiento; mientras que en la segunda capa, más detallada, debe incorporarse una descripción más detallada de las finalidades del tratamiento.

${ }^{45}$ La regla general en cuanto a la exteriorización del consentimiento es que éste sea inequívoco, esto es, que derive de una clara acción afirmativa. En esta línea el GT núm. 29 concreta en sus estudios una serie de aclaraciones sobre la forma de prestar el consentimiento: a) puede obtenerse mediante una declaración verbal grabada, si bien es preciso tener en cuenta la información que se proporciona al interesado antes de la indicación de consentimiento; b) el mero hecho de continuar con un servicio no implica, per se, indicación activa de haber realizado dicha opción; c) el consentimiento no puede obtenerse mediante la misma acción por la que un usuario acuerda un contrato o acepta los términos o condiciones generales de un servicio; y d) no cabe permitir, en palabras del RGPD, mecanismos de

Revista de Direito Brasileira | Florianópolis, SC | v. 22 | n. 9 | p.90-100 |Jan./Abr. 2019
} 
aceptar el tratamiento de los datos de carácter personal que le conciernen, como una declaración por escrito, inclusive por medios electrónicos, o una declaración verbal. Esto podría incluir marcar una casilla de un sitio web e internet, escoger parámetros técnicos para la utilización de servicios de la sociedad de la información, o cualquier otra declaración o conducta que indique claramente en este contexto que el interesado acepta la propuesta de tratamiento de sus datos personales. El silencio, las casillas ya marcadas, o la inacción, no constituyen consentimiento.

Este consentimiento debe darse para todas las actividades de tratamiento realizadas con el mismo o los mismos fines. Cuando el consentimiento tenga varios fines, debe darse para cada uno de ellos y si debe darse en función de una solicitud por medios electrónicos, la solicitud debe ser clara, concisa y no perturbar innecesariamente el uso del servicio para el que se presta.

Tratándose de datos personales con fines de investigación científica no es posible, con frecuencia, determinar totalmente la finalidad del tratamiento en el momento de su recogida. En estos casos, debe permitirse a los interesados dar su consentimiento para determinados ámbitos de investigación científica que respeten las normas éticas reconocidas para la investigación científica. Los interesados deben tener la oportunidad de dar un consentimiento solo para determinadas áreas de investigación o partes de proyectos de investigación, en la medida en que así lo permita la finalidad perseguida en el caso concreto.

Cuando el tratamiento de los datos personales de la persona física se lleva a cabo con el consentimiento del interesado, el responsable del tratamiento debe ser capaz de demostrar que aquél ha dado su consentimiento a la operación de tratamiento. En particular, en el contexto de una declaración por escrito realizada sobre otro asunto, debe haber garantías de que el interesado es consciente del hecho de que da su consentimiento y de la medida en que lo hace. Debe proporcionarse un modelo de declaración de consentimiento elaborado previamente por el responsable del tratamiento con una formulación inteligible y de fácil acceso que emplee un lenguaje claro y sencillo, y que no contenga cláusulas abusivas.

Para que el consentimiento sea informado el interesado debe conocer, como mínimo, la identidad del responsable del tratamiento y los fines del tratamiento a los cuales están destinados sus datos personales. El consentimiento no puede considerarse libremente prestado cuando el interesado no goza de verdadera o libre elección, o bien no puede denegar o retirar su consentimiento sin sufrir perjuicio alguno.

Para garantizar que el consentimiento se ha dado libremente, éste no debe constituir un fundamento jurídico válido para el tratamiento de datos personales en un caso concreto en el que exista un desequilibrio claro entre el interesado y el responsable del tratamiento, en particular cuando dicho responsable sea una autoridad pública y sea por lo tanto improbable que el consentimiento se haya dado libremente en todas las circunstancias de dicha situación particular.

Se presume que el consentimiento se ha dado libremente cuando no permita autorizar por separado las distintas operaciones de tratamiento de datos personales pese a ser adecuado en el caso concreto, o cuando el cumplimiento de un contrato, incluida la prestación de un servicio, sea dependiente del consentimiento, aun cuando éste no sea necesario para su cumplimiento.

En orden al consentimiento en el caso de menores, conviene precisar que el consentimiento del titular de la patria potestad o tutela no debe ser necesario en el contexto de servicios preventivos o de asesoramiento ofrecidos directamente a los niños. Señalar, por último, que tratándose de tratamientos que pudieren entrañar un mayor peligro, se exige un consentimiento reforzado, lo cual se concreta en que éste sea explícito (vgr. en el caso de categorías especiales de datos, en la elaboración de perfiles, o cuando estemos ante ciertos casos de transferencia internacional de datos $)^{46}$.

exclusión voluntaria que requieran intervención del interesado para evitar el acuerdo como, por ejemplo, la incorporación de casillas de exclusión voluntaria.

${ }^{46}$ En este sentido, véanse, por ejemplo, los arts. 9.2, 22.2.c y 49.1.a) RGPD.

Revista de Direito Brasileira | Florianópolis, SC | v. 22 | n. 9 | p. 90-100 |Jan./Abr. 2019 


\section{ÍNDICE BIBLIOGRÁFICO}

ADSUARA, B. "Derechos de rectificación, supresión (olvido) y portabilidad (de datos) y de limitación y oposición (al tratamiento)", en Tratado de Protección de Datos, dirigida por Rallo Lombarte, Tirant lo Blanch, Valencia, 2019.

ÁlVAREZ HERnÁndO, J. Practicum. Protección de Datos 2018, Thomson Reuters, Madrid, 2017.

AMÉRICO ALONSO, J. “Objeto y ámbito de aplicación”, en Tratado de Protección de Datos, dirigida por Rallo Lombarte, Tirant lo Blanch, Valencia, 2019.

BAJO, J.C. “Consideraciones sobre el principio de responsabilidad proactiva y diligencias (accountability)", en El nuevo marco regulatorio derivado del Reglamento de Protección de Datos, coordinada por López Calvo, Bosch, Barcelona, 2018.

DUASO CALÉS, R. "Los principios de protección de datos desde el diseño y la protección de datos por defecto”, en Reglamento General de Protección de Datos: hacia un nuevo modelo europeo de privacidad, coordinada por Álvarez Caro y Recio Gayo y dirigida por José Luis Pilar Mañas, Ed. Reus, Madrid, 2017.

FERNÁNEZ-SAMANIEGO, J - FERNÁNDEZ-LONGORIA, P. “El interés legítimo como principio para legitimar el tratamiento de datos”, en Tratado de Protección de Datos, dirigida por Rallo Lombarte, Tirant lo Blanch, Valencia, 2019.

MARTÍNEZ VÁZQUEZ, F. “La tramitación parlamentaria de la Ley Orgánica de Protección de Datos Personales y Garantía de los Derechos Digitales”, en Tratado de Protección de Datos, dirigida por Rallo Lombarte, Tirant lo Blanch, Valencia, 2019.

MARTOS, N. "Principios (arts. 6 a 11)” en El nuevo marco regulatorio derivado del Reglamento Europeo de Protección de Datos, coordinada por López Calvo, Bosch, Barcelona, 2018.

NÚÑEZ GARCÍA, L. “Responsabilidad y obligaciones del responsable y el encargado del tratamiento”, en Tratado de Protección de Datos, dirigida por Rallo Lombarte, Tirant lo Blanch, Valencia, 2019.

PUENTE ESCOBAR, A. "Principios y licitud del tratamiento”, en Tratado de Protección de Datos, dirigida por Rallo Lombarte, Tirant lo Blanch, Valencia, 2019.

PUYOL MONTERO, J. "Transparencia de la información y derecho de acceso de los interesados en la nueva normativa de protección de datos”, en Tratado de Protección de Datos, dirigida por Rallo Lombarte, Tirant lo Blanch, Valencia, 2019.

RALLO LOMBARTE, A. "Del derecho a la protección de datos a la garantía de nuevos derechos", en Tratado de Protección de Datos, dirigida por el propio autor, Tirant lo Blanch, Valencia, 2019. 
VALLESPÍN PÉREZ, D. El régimen profesional de los trabajadores autónomos y sus especialidades, Bosch, Barcelona, 2018.

VALLESPÍN PÉREZ, D. Litigios sobre consumo: acciones colectivas y especialidades procesales, Bosch, Barcelona, 2018.

VILASAU SOLANA, M. “El consentimiento general y de menores”, en Tratado de Protección de Datos, dirigida por Rallo Lombarte, Tirant lo Blanch, Valencia, 2019. 